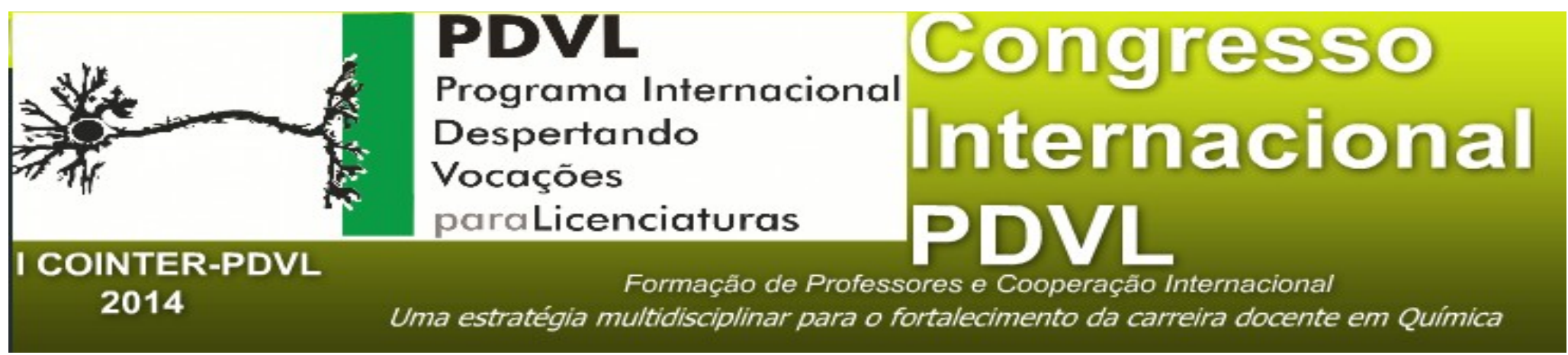

\title{
JOGO DIDÁTICO SOBRE RADIAÇÃO ESTELAR COMO FERRAMENTA DE COMPLEMENTAÇÃO NO ENSINO DE QUÍMICA NUCLEAR
}

Apresentação: Comunicação Oral

\begin{abstract}
Yane Lisset Barreto Vasquez ${ }^{11}$; Jorge Gonçalo Fernandez Lorenzo ${ }^{22}$; Yanderson Manoel Barreto Vasquez ${ }^{33}$; Edvaldo Amaro Santos Correia ${ }^{44}$
\end{abstract}

\section{Resumo}

Esse trabalho teve como objetivo utilizar a temática Radiação estelar para o estudo da Química Nuclear visando contextualizar o ensino da radiação, bem como minimizar a ausência de informações referentes a essa área tecnológica e fornecer subsídios para que o aluno pudesse compor sua própria visão crítica. Na perspectiva de instigar os estudantes a uma compreensão mais lúdica, foi utilizada a contextualização.

Tendo em vista que este modelo de contextualização se caracteriza por priorizar a autonomia do aluno como sujeito da aprendizagem, a atividade lúdica proposta foi voltada para a discussão e a retificação dos saberes. O instrumento de pesquisa foi um questionário pré e pós-aplicação do jogo lúdico e ocorreu no Instituto de Educação da Paraíba. O total da amostra contou com a participação de 20 alunos do $3^{\circ}$ ano do ensino médio no mês de junho de 2013.

Os resultados desta pesquisa mostraram uma ampliação das concepções dos discentes, que caracterizavam, inicialmente, a radiação sem aplicação prática e majoritariamente negativa, e

1 Licenciatura em Química/UFPB /yanelisset@hotmail.com

2 Licenciatura em Química /IFPB / jgflorenzo@hotmail.com

3 Licenciatura em História/UFPB / yandersomcpm22@hotmail.com

4 Engenharia Quimica. /IFPB / edvaldo.amaro@ifpb.edu.br 
passaram a compreender questões multidisciplinares, como: a origem dos elementos químicos e o processo de luminosidade das estrelas, dentre outros, por meio da contextualização, como a abordagem de questões sociais, com vistas a desenvolver atitudes e valores e à transformação da realidade social.

Palavras-Chave: química nuclear, radiação, jogo didático.

\section{Introdução}

A escolha da temática Radiação Estelar para o estudo e contextualização da Química Nuclear se formulou a partir de questionamentos instigantes que ocorrem frequentemente no último ano do ensino médio por estudantes que se propõem a repensar com mais constância e aprofundamento a cerca da ciência. Diante disto, a reflexão inicial se fundamentou em indagações de natureza multidisciplinar, tais como: "Por que os prótons ficam unidos no núcleo atômico se possuem mesma carga?”; "Dê onde efetivamente vêm os átomos?”. Estas foram as principais questões que serviram de motivação para o presente estudo, em busca de respostas que tivessem um nível de explicação científica suficientemente completa, objetivando a aplicação em sala de aula por meio de um tema com caráter contextualizador. No entanto, embora existam respostas a estas questões, sabe-se que estas são limitadas pela priorização de outros conhecimentos pelos professores de química, levando a uma abordagem em sala de aula de forma descontextualizada, resultando em num entendimento fragmentado.

Diante desta problemática é perceptível que ainda existe uma relutância dos discentes do ensino médio com relação à radioatividade que em grande parte, é cercada por uma visão negativa, tendo em vista os acontecimentos históricos que envolvem a radiação nuclear, com acidentes de grande impacto social e ambiental. Tem-se ainda o misticismo, consequência do senso comum, e muitas vezes equivocado, de que radioatividade é um conhecimento da química com um alto nível de abstração e dificuldade de entendimento.

Sendo assim, o estudo desse tema se faz necessário, pois serve como instrumento de análise e de proposta que utiliza a radiação estelar como tema para gerar conexões entre as respostas às essas referidas questões iniciais, com exemplos do cotidiano imersos pela tecnologia atual, envolvendo ainda a compreensão de fenômenos da química cósmica e de muitas outras aplicações dos diferentes tipos de radiações. Portanto, esse trabalho se fundamentou na construção e utilização de situações problemas, onde a contextualização envolveu principalmente debates e discussões em conjunto a cerca das diversas áreas da medicina, arqueologia, agricultura, e indústria que 
fundamentalmente se direcionem nas aplicabilidades da radiação.

Direcionado por essa visão, o presente trabalho foi desenvolvido tendo em vista o embasamento teórico das perspectivas de contextualização no ensino, baseadas nos documentos oficiais sobre a educação brasileira, a LDB e os PCNs. Nesse sentido, que pudessem proporcionar aos discentes um panorama mais amplo das relações sociais, ambientais e econômicas que a área nuclear possibilita subsidiar, a fim de promover a elucidação de seus aspectos benéficos e maléficos para, dessa forma, dispor ao aluno uma concepção mais completa da Química Nuclear. O objetivo de direcionar o presente trabalho nessa perspectiva é que o aluno tenha as ferramentas necessárias para construir sua própria visão em torno do assunto e, mais do que isso, desmistificar conceitos equivocados da radioatividade. Por isso, foram desenvolvidas atividades de caráter experimental, lúdico e, principalmente, contextualizador durante a aplicação desse trabalho em sala de aula.

\title{
Fundamentação Teórica
}

A Química possui particularidades que são próprias de sua natureza. Sendo assim, a divisão dessa ciência ocorre em níveis fundamentais como: nível macroscópico, que trata das propriedades de objetos grandes e visíveis, nível microscópico, que se baseia na interpretação de fenômenos em termos de arranjos de átomos, nível denominado de simbólico, que representa a descrição dos fenômenos químicos por meio de símbolos químicos e equações matemáticas (ATKINS, 2012).

É imprescindível considerar que quem lida com a prática cientifica e, também com o ensino de química, tenha em vista uma maior reflexão a cerca dos níveis que fundamentam essa ciência, pois este parâmetro serve de direcionamento na abordagem ou no método aplicado para o ensino dos conhecimentos químicos.

Partindo deste pressuposto, sabe-se, entretanto, que, de acordo com Lôbo (2008 p.91):

\begin{abstract}
No contexto do ensino, um dos aspectos mais discutidos por educadores em Ciência é a dificuldade de compreensão dos conceitos científicos pelos alunos. No ensino de Química, conceitos derivados da Mecânica Quântica e utilizados na compreensão de vários aspectos relativos às ligações químicas e à estrutura molecular apresentam alto grau de dificuldade de compreensão, em função da necessidade de maior abstração. Como diz Bachelard, a Química contemporânea não é mais uma ciência de memória, mas uma Química matemática, uma Química teórica, fundada a partir da união com a Física teórica, uma Química teórica-Física.
\end{abstract}

Dessa forma, essa dificuldade tem sido analisada principalmente quando se trabalha com conceitos para explicar fenômenos do mundo submicroscópico, e a química nuclear se enquadra 
nessa mesma realidade. Primeiro porque o objeto de estudo da química nuclear é o cerne do átomo, ou seja, o seu núcleo, que é extremamente pequeno e que se torna, portanto invisível. Além disso, tem-se ainda a concepção negativa dessa área tecnológica baseada, sobretudo, em misticismos do senso comum. Nesse contexto, é notória também a renovação dos padrões de cientificidade, pois o próprio estudo da estrutura do núcleo atômico evolui concomitantemente com a comunicação para a reelaboração de conceitos em sala de aula.

Diante desse panorama, a contextualização tem sido apontada por educadores e estudiosos do ensino como uma perspectiva para nortear a aprendizagem, pois é um meio que viabiliza uma visão mais prática dos conhecimentos estudados, ou seja, insere os discentes em um contexto onde se podem analisar aspectos que vão além dos conteúdos disciplinares. Tem-se também que a contextualização se caracteriza por possibilitar o discente resgatar o seu conhecimento prévio a fim de estabelecer conexões com o tema abordado e o contexto em que se aplica o saber compreendido. Logo, o modo de ensinar utilizando da contextualização permite que o contexto tenha como finalidade dar significação para o aprendizado mais geral e abstrato.

Partindo dessa fundamentação, um dos primeiros referenciais da educação nacional, a Lei de Diretrizes e Bases da Educação Nacional (LDB/96) estabelece no Artigo 35, incisos II e III, que ao final da educação básica o educando deve ter:

\footnotetext{
“II - a preparação básica para o trabalho e a cidadania do educando como pessoa humana, incluindo a formação ética e o desenvolvimento da autonomia intelectual e do pensamento crítico;

III - a compreensão dos fundamentos científico-tecnológicos dos processos produtivos, relacionando a teoria com a prática, no ensino de cada disciplina.”
}

As considerações gerais sobre a lei indicam a necessidade de construir novas alternativas. Embora não se use o termo contextualização, o segundo inciso menciona a perspectiva de que o discente seja formado para o pensamento crítico, ou seja, o colocando no processo ativo de aprendizagem que, de certa forma, remete ao principal objetivo da contextualização. Além da autonomia intelectual, a formação ética imposta no mesmo inciso direciona as implicações que envolvem as relações humanas e a preocupação com a sociedade em que se vive, colocando, portanto o aluno como sujeito que possa exercer o conhecimento compreendido de forma correta e vislumbrando, também, o seu papel como cidadão.

O inciso III ainda vai além e prevê que os fundamentos científico-tecnológicos estejam relacionando a teoria com a prática no ensino de cada disciplina. Nesse sentido a lei permeia a 
concepção de que o desenvolvimento voltado para os conhecimentos práticos das disciplinas, estando à química incluída, priorize a racionalidade do aluno, e isto deve estar em consonância da teoria com a prática. As Diretrizes Curriculares Nacionais do Ensino Médio - DCNEM, na resolução da CEB, evidencia o uso da contextualização como sendo um dos estruturadores dos currículos do ensino médio devendo, portanto, ser adotado.

Tendo em vista essa totalidade de contribuições advindas da contextualização em que o docente tem a necessidade de enfrentar esse desafio, ou seja, tornar o ensino de Química cada vez mais crítico, reflexivo e menos voltado para a memorização de conhecimentos. A ludoquímica tem se mostrado como uma alternativa de complementação de ensino, pois se encaixa nos objetivos que a contextualização e propõe que dentre as contribuições do uso de jogos didáticos segundo Miranda (2001) vários objetivos podem ser atingidos a partir da utilização dos jogos, como os relacionados à cognição (desenvolvimento da inteligência e da personalidade, fundamentais para a construção de conhecimentos); à afeição (desenvolvimento da sensibilidade e da estima e atuação no sentido de estreitar laços de amizade e afetividade); à socialização (simulação de vida em grupo); à motivação (envolvimento da ação, do desfio e mobilização da curiosidade) e à criatividade.

A análise no uso dessa ferramenta de complementação em sala de aula também se caracteriza por fornecer uma autonomia do aluno diante de desafios que são colocados diante de questionamentos feitos durante o jogo aplicado e o professor também se fundamenta como um intermediador desse processo, pois, para Vigotsky (2007), o aluno exerce um papel ativo no processo de aprendizagem, por apresentar condições de relacionar o novo conteúdo a seus conhecimentos prévios, e o professor se torna o responsável por criar zonas de desenvolvimento proximal, ou seja, proporciona condições e situações para que o aluno transforme e desenvolva em sua mente um processo cognitivo mais significativo.

Em síntese, as atividades lúdicas não levam à memorização mais fácil do assunto abordado, mas induzem o aluno a raciocinar, a refletir. Ou seja, considerando todos esses aspectos favoráveis no uso de outros modelos ou ferramentas que auxiliam no processo de aprendizagem, usar esses recursos a favor do docente tem como consequências alternativas que embora fujam do tradicional, envolve o discente a uma construção de conhecimento de forma cada vez mais efetiva.

Sendo assim esse trabalho foi desenvolvido como parte de um conjunto mais amplo referente a temática radiação estelar no ensino de Química nuclear, mas cada atividade proposta teve um caráter contextualizador e a avaliação foi feita por etapas, dessa forma o lúdico utilizado foi aplicado ao final desse projeto. 


\section{Metodologia}

No desenvolvimento metodológico deste estudo utilizou-se a pesquisa do tipo exploratória, que é definida, segundo Gil (2010, p. 27), com as características de:

[...] proporcionar visão geral, de tipo aproximativo, acerca de um determinado fato. Este tipo de pesquisa é realizado especialmente quando o tema escolhido é pouco explorado e torna-se difícil sobre ele formular hipóteses precisas e operacionalizáveis.

Nessa perspectiva, a forma de abordagem utilizada foi uma pesquisa qualitativa quantitativa, tendo em vista que o instrumento de pesquisa é composto por um questionário semi-estruturado inicial e final possuindo questões que puderam ser avaliadas como em abertas e fechadas. Tal aspecto é o que justifica esse estudo possuir ambas as características, ou seja, interpretar as informações quantitativas através da estatística na análise dos dados e os dados qualitativos através das observações, comparações e interpretações dos resultados. A amostra consistiu de um total de 20 estudantes do $3^{\circ}$ ano do ensino médio do Instituto de Educação da Paraíba - IEP, escola pública estadual na cidade de João Pessoa - PB. Contando um encontro com duas aulas de 45 minutos, para a aplicação do jogo e foi feito durante o mês de junho de 2013.

\section{A elaboração do lúdico}

Foi feito com os seguintes materiais: tesoura, cartolina, papel ofício e cola. Inicialmente foi elaborado um tabuleiro no Word e adicionado questões referentes a temática de radiação estelar sobre os conteúdos de química nuclear, posteriormente o tabuleiro foi impresso em papel ofício e colado sobre a cartolina. Após isso, foram feitos os cartões, onde cada um delas possuía um tipo de radiação nuclear (alfa $-\alpha$, beta $-\beta$, gama- $\gamma$ ) e também foi impresso, além disso, um dado com alterações dos números 4, 5 e 6 e trocados pelo nome “radiação”. As regras consistiam em:

1- Em grupos de 4 a 6 pessoas, jogando 2 contra dois ou 3 contra três.

2- No grupo de 4 ou 6 pessoas, estes receberão 1 tabuleiro e um monte de cartões, peças para avançar no tabuleiro e um dado.

3- Uma das equipes sorteia-se para quem irá iniciar o jogo, a equipe que inicia joga o dado e caso dê um número ele se direciona a quantidade de casas indicativas no dado no tabuleiro central, porém se der o nome "radiação” no dado ele vai para a tabela lateral.

4- Os alunos do mesmo grupo (dois ou três, dependendo de quantos alunos formam a equipe) poderão discutir entre si qual a resposta para a pergunta. 
Na hipótese que os alunos acertem a resposta da pergunta do tabuleiro central, do lado do tabuleiro central têm em cada casa números nos retângulos de cor azul que indica quantas casas eles poderão andar. À medida que no dado der o nome "radiação" o aluno se direciona ao tabuleiro lateral de sua equipe onde existem espaços para colocar o cartão indicando qual tipo de radiação foi emitido pelo elemento químico. Já na hipótese que os alunos não saibam da resposta, ou errarem, o número indicativo nos retângulos laterais de cor vermelha irá indicar as casas que terão que retroceder. E esse avanço ou retrocesso das casas no jogo foi categoricamente usado considerando o nível de dificuldade das perguntas existentes no tabuleiro. A equipe que avançasse mais casas e completasse a tabela lateral de emissão radioativa ganha o jogo.

Antes de aplicar do jogo, um questionário inicial foi entregue aos discentes com o eminente proposito analisar as concepções que os alunos adquiram durante as aulas que foram feitas usando a temática radiação estelar no que se refere a assunto de química nuclear, após aplicação do questionário inicial os alunos fizeram uso do jogo, as perguntas de acordo com a tabela 1.

\begin{tabular}{|c|c|c|c|c|}
\hline \multicolumn{5}{|c|}{ Análise do questionário inicial } \\
\hline Questões & $\begin{array}{c}\text { 1) Como você } \\
\text { explicaria a } \\
\text { luminosidade das } \\
\text { estrelas tendo em vista } \\
\text { seu conhecimento } \\
\text { prévio sobre o assunto } \\
\text { e as discussões em } \\
\text { sala de aula sobre o } \\
\text { tema? }\end{array}$ & $\begin{array}{l}\text { 2) O que faz um } \\
\text { elemento químico } \\
\text { ser radioativo? }\end{array}$ & $\begin{array}{l}\text { 3) O que difere uma } \\
\text { radiação nuclear de } \\
\text { uma radiação } \\
\text { eletromagnética? Cite } \\
\text { exemplos. }\end{array}$ & $\begin{array}{l}\text { 4) A radiação } \\
\text { nuclear é um } \\
\text { fenômeno } \\
\text { natural? }\end{array}$ \\
\hline $\begin{array}{l}\text { Percentual } \\
\text { de acertos }\end{array}$ & $65 \%$ & $70 \%$ & $85 \%$ & $75 \%$ \\
\hline
\end{tabular}

Tabela 1: Questionário antes da aplicação do tabuleiro sobre radiação estelar. Fonte: Própria

\section{Resultados e Discussões}

A análise dos dados possibilitou desvelar resultados significativos sobre as concepções dos alunos e como eles se apropriaram das ideias discutidas no projeto com o uso da temática radiação estelar. A princípio é possível evidenciar que os resultados obtidos na análise prévia indica um alto índice de acerto que também é justificado pelo jogo ter sido uma complementação que os alunos 
aprenderam durante outras atividades feitas no período de aplicação desse projeto e também de seus conhecimentos prévios, ou seja, tais percentuais indicam que os discentes efetivamente compreenderam a proposta do conteúdo de química nuclear aliado à temática e consequentemente 0 jogo foi apenas uma confirmação de que as concepções adquiridas antes ficaram alicerçadas com um bom índice de entendimento.

Após os discentes iniciarem o uso do jogo, durante o processo foi perceptível evidenciar a interação e discussão a cerca das questões que o jogo trazia, o resultado foi muito satisfatório pois os alunos puderam responder e explicar fenômenos da radiação de forma conjunta e interativa, onde o proposito de acertar ou errar não era o aspecto mais importante da aplicação do jogo e sim o direcionamento que o grupo faziam em auxiliar os colegas que tinham ainda dificuldades sobre o conteúdo trabalhado, fazendo uns aos outros as retificações necessárias, as dúvidas eram esclarecidas nas equipes que disputavam e sempre tal discussão sendo feita com a intermédio do professor. Na foto 1 e 2 pode-se visualizar os alunos durante a aplicação do jogo.

Além disso, recurso usado, ou seja, o tabuleiro da radiação estelar se direcionou como um aspecto de análise da interação entre alunos e professor na identificação das dificuldades enfrentadas pelos alunos a cerca do conhecimento químico trabalhado, esclarecimentos e também possibilitou a discussão entre os discentes participantes da atividade lúdica bem a aproximação do conhecimento químico de forma divertida e interessante.

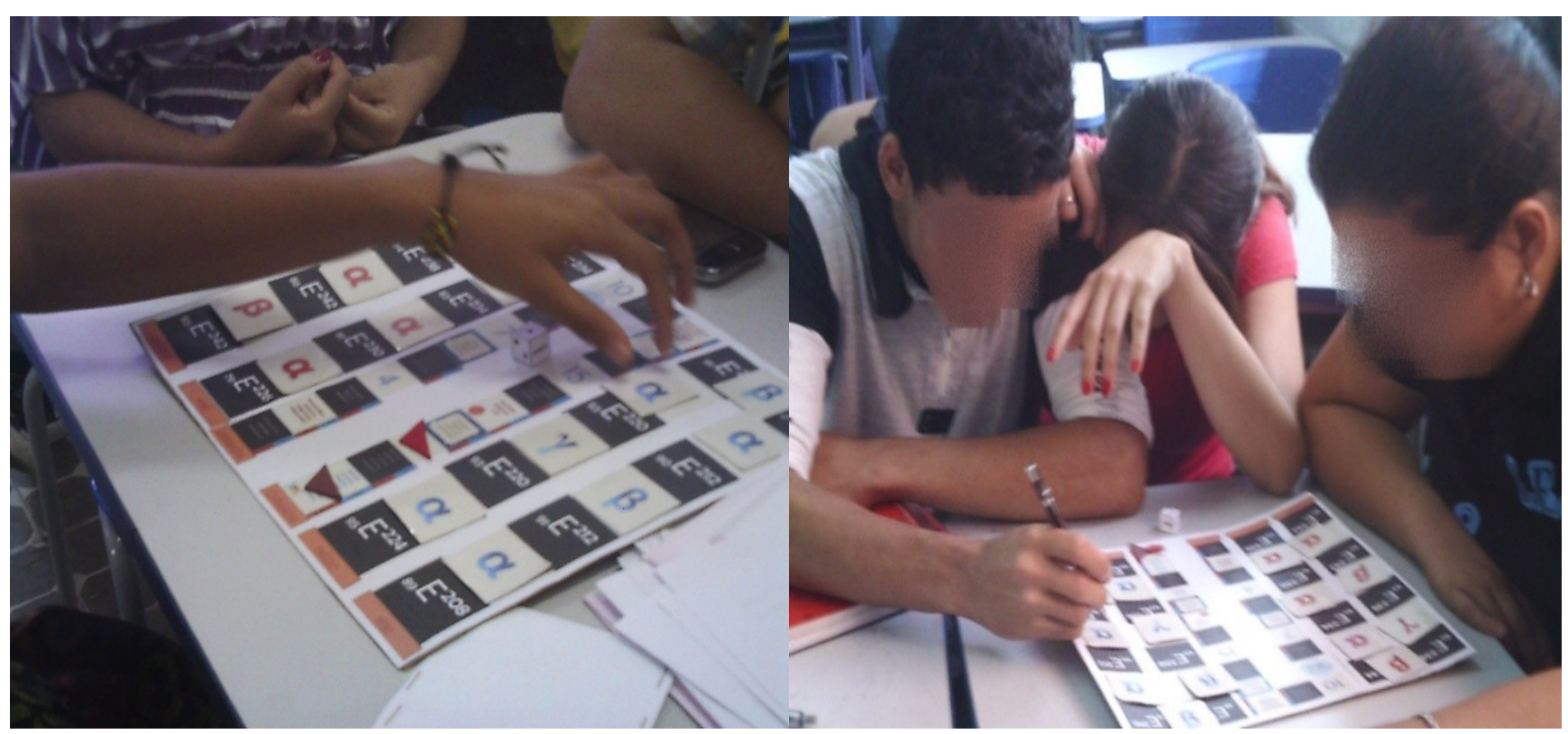

Foto 1 e 2: Alunos utilizando o jogo sobre radiação estelar. Fonte: Própria

Após a aplicação do jogo, os alunos responderam a um questionário final que foram as mesmas questões aplicadas no questionário prévio, os resultados podem ser evidenciados conforme 
o gráfico 1.

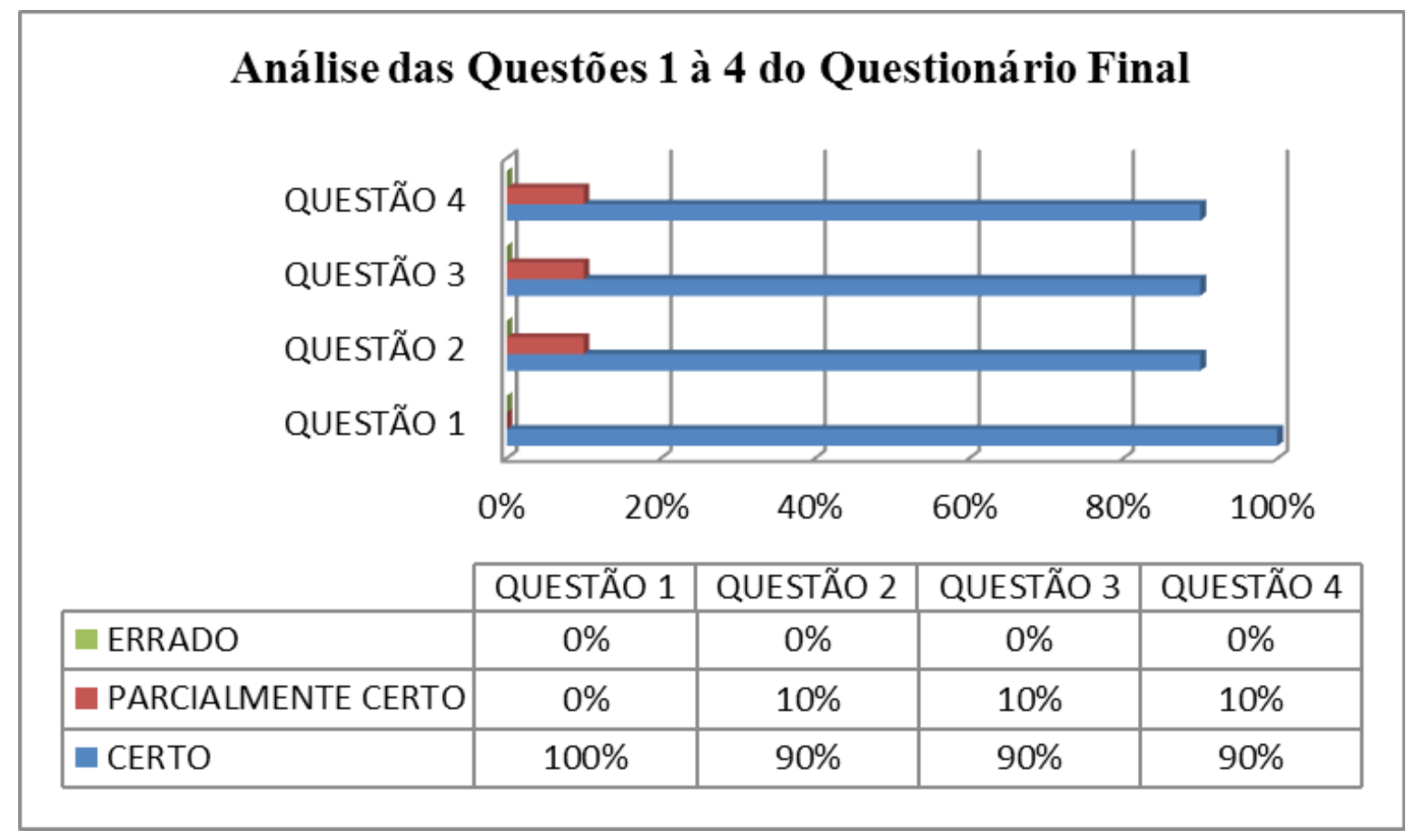

Gráfico 1: Resultados obtidos após aplicação do questionário final

O detalhamento final apresentado no gráfico 1, é resultado de uma efetiva apropriação do conhecimento químico e sobre a temática abordada. Os resultados puderam apontar que, ao final do encontro, um resultado de aceitação majoritária, em aspectos como motivação, curiosidade, participação e, principalmente, reflexão, pois este último fator foi imprescindível para suscitar os aspectos anteriores e de significação ao contexto estudado. Além dessa constatação, foi perceptível também constatar os percentuais com altos índices de acertos e consequentemente, uma ínfima porcentagem de parcialmente correto, e porcentagem nula de erros. Mesmo considerando o menor índice de acerto, de 90\%, isto comprova que a maior parte da totalidade da amostra soube apresentar os saberes discutidos com racionalidade e prática do assunto.

\section{Conclusões}


Diante das análises e detalhamento sobre os resultados das atividades propostas por meio do tema Radiação Estelar, o caráter contextualizador deste trabalho conseguiu efetivar os objetivos de priorizar a racionalidade do aluno. Repensar a construção do conhecimento químico visando a perspectiva atuante do aluno faz o docente recorrer a um ensino contextualizado, com o eminente objetivo de abordar os conhecimentos da química tendo em vista a consonância da teoria com a prática. Além disso, isto significa estar instigado a entender determinado fenômeno. É preciso estar sempre construindo uma nova indagação em torno do que se pretende compreender, sendo essa a ferramenta principal para desfragmentar a visão do senso comum, retificar o que já se conhece e complementar o entendimento de forma completa.

Sendo assim, a abordagem da Química Nuclear pôde ser feita de forma que o conhecimento inferido não enfatize o caráter exclusivamente negativo que se tem sobre a radiação ou que esteja desconfigurarando o conhecimento. Sempre é possível buscar um tratamento e um reordenamento conceitual de determinadas conhecimentos da química, visando à superação da visão compartimentada. O uso do tema radiação estelar pôde ampliar a visão do aluno, com questões que atualmente se tem interesse de entender com maior detalhamento, questões estas que não estão tendo atenção em sala de aula e que passa a se instituir nos discentes uma incompletude de falsos entendimentos. E principalmente, fornecer subsídios para que o aluno construa sua própria visão repastada por inúmeros contextos que a radiação faz parte, bem como as multidisciplinaridades de áreas ao qual tem influência, e mais do que, isso desmistificar conceitos equivocados da radioatividade.

\section{Referências}

ATKINS, P.; JONES, L. Princípios de Química: Questionando a vida moderna e o meio ambiente, 5. ed.[s.L.]: Bookman, 2012

BRASIL, MEC. Lei $n^{\circ}$ 9.394, de 20 de dezembro de 1996. Diretrizes e Bases da Educação Nacional. p. (13-14). Disponível em: <http://portal.mec.gov. br/arqui vos/pdf/ldb.pdf >. Acesso em: 17 de outubro de 2014.

BRASIL (País) Secretaria de Educação Média e Tecnológica - Ministério da Educação e Cultura. 
Parâmetros Curriculares Nacionais do Ensino Médio. Brasília: MEC/SEMTEC, p. 82. 2000.

GIL, A. C. Como elaborar projetos de pesquisa. São Paulo: Atlas, p.27. 1991.

LOBO, Soraia Freaza. O ensino de química e a formação do educador químico, sob o olhar bachelardiano. Ciênc. educ. (Bauru) [online]. 2008, vol.14, n.1, pp. 89-100. Disponível em: < http://www.scielo.br/pdf/ciedu/v14n1/06.pdf> Acesso em: 27 de outubro de 2014

MIRANDA, S.. No Fascínio do jogo, a alegria de aprender. Ciência Hoje, v.28, p. 64-66, 2001.

SANTANA, E. M. A Influência de atividades lúdicas na aprendizagem de conceitos químicos. In: SENEPT, 2008, Belo Horizonte. Anais... São Paulo: Universidade de SãoPaulo, Instituto de Física - Programa de Pós-Graduação, 2008.

ZANON, D.A.V.; GUERREIRO, M.A.S.; OLIVEIRA, R.S. Jogo didático Ludo Químico para o ensino dos compostos orgânicos: projeto, produção, aplicação e avaliação. Ciência e Cognição. v. 13, 2008. p. 72-81. Disponível:<http://www.cienciasecognicao.org/pdf/v13/m318239.pdf>. Acesso em: 15 de outubro de 2014. 